\title{
Lifetime Analysis of Rubber Gasket Composed of Methyl Vinyl Silicone Rubber with Low-Temperature Resistance
}

\author{
Young-Doo Kwon, ${ }^{1}$ Seong-Hwa Jun, ${ }^{2}$ and Ji-Min Song ${ }^{3}$ \\ ${ }^{1}$ School of Mechanical Engineering \& IEDT, Kyungpook National University, No. 80 Daehakro, Daegu 702-701, Republic of Korea \\ ${ }^{2}$ Institute of Engineering Design Technology, Kyungpook National University, No. 80 Daehakro, Daegu 702-701, Republic of Korea \\ ${ }^{3}$ Graduate School of Mechanical Engineering, Kyungpook National University, No. 80 Daehakro, Daegu 702-701, Republic of Korea
} Correspondence should be addressed to Young-Doo Kwon; ydkwon@knu.ac.kr Received 9 April 2015; Accepted 18 May 2015

Academic Editor: Filippo Ubertini

Copyright (C) 2015 Young-Doo Kwon et al. This is an open access article distributed under the Creative Commons Attribution License, which permits unrestricted use, distribution, and reproduction in any medium, provided the original work is properly cited.

\begin{abstract}
Most machines and instruments constantly require elastomeric materials like rubber for the purposes of shock absorption, noise attenuation, and sealing. The material properties and accurate lifetime prediction of rubber are closely related to the quality of machines, especially their durability and reliability. The properties of rubber-like elastomers are influenced by ambient conditions, such as temperature, environment, and mechanical load. Moreover, the initial properties of rubber gaskets must be sustained under working conditions to satisfy their required function. Because of its technical merits, as well as its low cost, the highly accelerated life test (HALT) is used by many researchers to predict the long-term lifetime of rubber materials. Methyl vinyl silicone rubber (VMQ) has recently been adopted to improve the lifetime of automobile radiator gaskets. A four-parameter method of determining the recovery ability of the gaskets was recently published, and two revised methods of obtaining the recovery were proposed for polyacrylate (ACM) rubber. The recovery rate curves for VMQ were acquired using the successive zooming genetic algorithm (SZGA). The gasket lifetime for the target recovery (60\%) of a compressed gasket was computed somewhat differently depending on the selected regression model.
\end{abstract}

\section{Introduction}

Most machines and instruments constantly require elastomeric materials like rubber for the purposes of shock absorption, noise attenuation, and sealing [1]. The rubber elastomer is classified into three types: natural rubber (NR), synthetic rubber (SR), and NR + SR blended at a given ratio. SR exhibits many excellent properties in terms of mechanical performance. NR is often inferior to certain SRs, especially with respect to thermal stability and compatibility with petroleum products [2]. The SR ethylene propylene diene monomer (EPDM) rubber, which has the characteristic of high-temperature resistance, has been mainly adopted for a radiator gasket of an automobile until now. However, methyl vinyl silicone rubber (VMQ) has recently begun to be used as a radiator gasket material compatible with an extreme temperature range and low temperatures, according to SAE J200, because previous gasket design criteria stated that low-temperature applications for automobiles reached temperatures in the range of $-70^{\circ} \mathrm{C}$ to $-55^{\circ} \mathrm{C}$ by major automotive companies. The VMQ specimen used in this study is made from the final master batch of Burim FMB Co. in ROK, which has been made from the silicone base of Dow Corning Co. by adding 1 PHR of curing agent and 0.5 PHR of pigment.

In this study, we predict the lifetime of a VMQ radiator gasket recently developed by a local company using the method proposed in 2014 [3]. Generally three methods are used for the lifetime prediction of a rubber gasket. The most practical method with mathematical concepts is the highly accelerated life test (HALT), which applies temperatures higher than the service temperature over a short period. Using this method, the long-term lifetime of a gasket at lower temperatures can be predicted by extrapolating the data [4]. The second lifetime prediction method under service conditions is economically disadvantageous because of its long testing time, high cost, and labor requirements. The third 
method is to rely on an experienced engineer specializing in rubber materials, which is less reliable and does not yield objective results.

The HALT is a test methodology that accelerates the degradation of material properties using several specimens, and it has been used by many researchers during the material development stage and design process. This test is also commonly applied to rubber materials for gaskets and dampers and facilitates the identification and resolution of weaknesses in new product designs. The methodology diminishes the probability of in-service failures; that is, it increases product quality by virtue of reliability and decreases the development cost and time [5]. The HALT for VMQ was performed at temperatures of $150-200^{\circ} \mathrm{C}$ under a compression rate of $30 \%$, which is the actual compression rate under service conditions for the radiator gasket. Additionally, a low-temperature test at $-70^{\circ} \mathrm{C}$ was performed under the same compression rate.

In this method of lifetime prediction, the Arrhenius model [6] is simpler and more effective for most cases than the Eyring model [7] and uses experimental data. The lifetime of the gasket is defined as the time when the recovery rate meets $60 \%$ of the target value after undergoing a $30 \%$ compression rate, which depends on the service temperature, whereas ISO 11346 [8] stipulates that the failure time of chemical materials is the point where its initial properties are reduced to $50 \%$.

According to most references investigating a lifetime evaluation adopting the linear Arrhenius equation [9] for the $\ln (t)-(1 / T)$ relationship, where $t$ is the lifetime and $T$ is the temperature, small errors in the lifetime at high temperatures from the HALT evaluation may lead to large errors in the predicted lifetime at low temperatures. Unlike most papers, which do not consider the recovery $\ln (t)$ curve, one study made use of four parameters instead of two parameters in the Arrhenius plot to accurately draw the recovery $\ln (t)$ curve and correctly determine the long-term lifetime.

With accurate lifetime predictions at high temperatures, the linear Arrhenius model in the $\ln (t)-(1 / T)$ plane can yield correct quantitative analysis of the lifetime of VMQ at a low working temperature.

\section{Successive Zooming Genetic Algorithm Method for Optimum Parameters}

The successive zooming genetic algorithm (SZGA) method is used to achieve a smart reduction of the search space around the candidate optimum point $[10,11]$. Although this method can also be applied to a general genetic algorithm (GA), it was applied to a micro-genetic algorithm (MGA). The computing procedure of the SZGA is as follows. First, the initial population is generated and an MGA is applied. Subsequently, after every 100 generations, the optimum point with the highest fitness is identified. Second, the search domain is reduced to $\left(X_{\text {kopt }}-\alpha^{k} / 2, X_{\text {kopt }}+\alpha^{k} / 2\right)$, and the optimization procedure continues based on the reduced domain; that is, a new initial population is generated within the new boundaries. This reduction of the search domain increases the resolution of the solution, and the procedure is repeated until the identified solution is satisfactory $(\delta$ is the error ratio, $X_{\text {kopt }}$ is the optimum point after $(100 \times$ $k$ )th generation, $\alpha$ is the zooming factor, and $N_{\text {zoom }}$ is the number of zooming operations). $\delta$ is the relative ratio of $\left(F_{\mathrm{opt}}^{k}-F_{\mathrm{opt}}^{k-1}\right) / F_{\mathrm{opt}}^{k}$, and $F_{\mathrm{opt}}^{k}$ and $F_{\mathrm{opt}}^{k-1}$ are the $k$ th and $(k-1)$ th optimum function values. The critical ratio $\delta_{0}$ is $1 \times 10^{-6}$. To fit the recovery rate curve of the polyacrylate (ACM) rubber gasket, the optimal parameters of the smallest mean squared error (MSE) [12] were obtained using this SZGA method. Figure 1 shows the flowchart and the schematics of the SZGA:

$$
\text { Mean squared error (MSE) }=\frac{1}{n} \sum_{i=1}^{n}\left(f\left(\mathbf{k}, x_{i}\right)-D_{i}\right)^{2},
$$

where k: unknown parameters.

\section{Methods of Predicting the Quantitative Lifetime of a VMQ Gasket}

Methods of mathematically predicting the quantitative lifetime are introduced in this section. To obtain an Arrhenius plot of the long-term lifetime, we first needed to fit the recovery rate curve for a given temperature to obtain the lifetime corresponding to a recovery rate of $60 \%$. Two methods of fitting curves for the ACM were adopted here for the VMQ [3]. The recovery rate of a rubber gasket was assumed to be two exponential functions represented by four parameters. The recovery rate curves were fit using the four optimized parameters, and the lifetimes were solved from the obtained functions. Before we explain the methods of obtaining lifetimes at each given temperature by adopting recovery models, let us first explain the prediction of long-term lifetime using the Arrhenius plot.

3.1. Arrhenius Equation and Plot. An Arrhenius equation presents the kinetic rate $K$ as a function of the reciprocal of the temperature $T$ in Kelvin [5]. This model is used widely to estimate the reciprocal effect of temperature as

$$
K=A e^{-E_{a} / R T} .
$$

For a single rate-limited thermally activated process, an Arrhenius plot gives a straight line as a function of the activation energy and temperature as

$$
\ln (K)=\ln (A)-\frac{E_{a}}{R}\left(\frac{1}{T}\right),
$$

where $K$ is the rate constant, $A$ is the preexponential factor, $R$ is the gas constant, $T$ is the absolute temperature $\left({ }^{\circ} \mathrm{K}\right)$, and $E_{a}$ is the activation energy.

Equation (3) can be rearranged to give a time-temperature relation by applying $t \propto 1 / K$, as

$$
\ln (t)=\ln \left(\frac{1}{A}\right)+\frac{E_{a}}{R}\left(\frac{1}{T}\right) .
$$

The lifetimes for higher temperatures are plotted in Arrhenius form, and the long-term lifetimes may be predicted by linearly extrapolating the given data in the semilog 


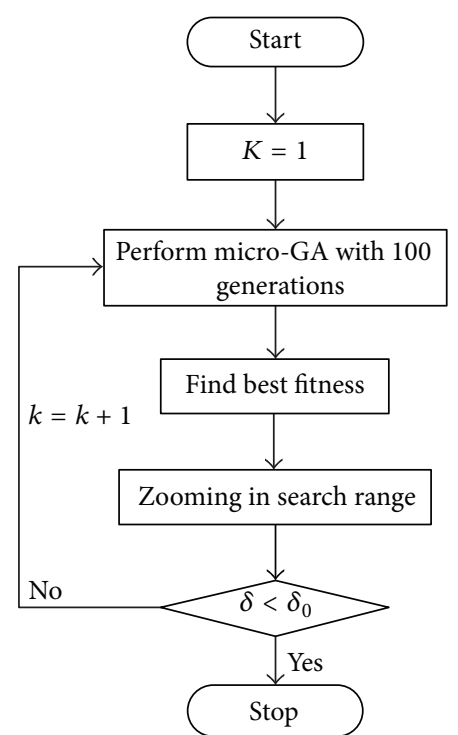

$\delta:$ error ratio $=10 e-6$

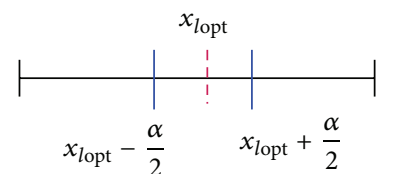

$X_{1}: 0 \sim 1$

$Z_{1}: 0 \sim 1$

Length of search range $=1$

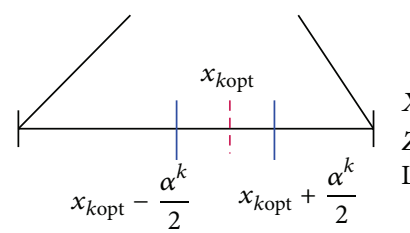

$X_{l}: X_{(l-1) \mathrm{opt}}-\frac{\alpha^{l-1}}{2} \sim X_{(l-1) \mathrm{opt}}-\frac{\alpha^{l-1}}{2}$
$Z_{l}: 0 \sim 1$

Length of search range $=\alpha^{l-1}$

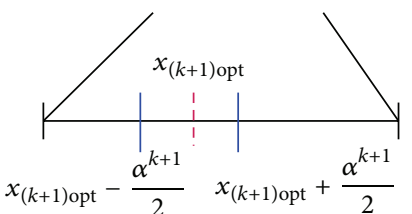

$X_{l+1}: X_{\text {lopt }}-\frac{\alpha^{l}}{2} \sim X_{\text {lopt }}-\frac{\alpha^{l}}{2}$

$Z_{l+1}: 0 \sim 1$

Length of search range $=\alpha^{l}$

$X_{k}$ : global variable (dimensionless)

$Z_{k}$ : local variable (dimensionless in zoomed range)

$k: 1 \sim N_{\text {zoom }}$

FIGURE 1: Flowchart and schematics of SZGA.

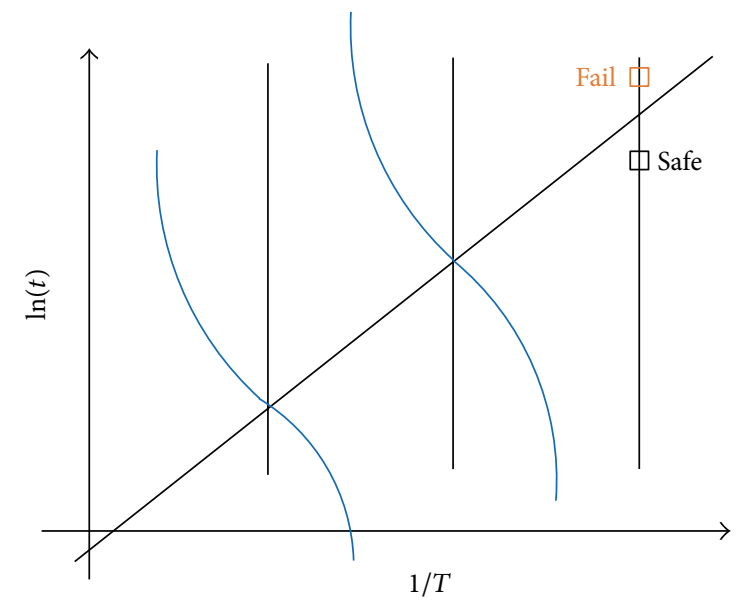

FIgURE 2: Arrhenius plot used to predict lifetime.

plane of $\ln (t)-(1 / T)$. Figure 2 shows a plot of the long-term lifetime prediction method using the Arrhenius plot. If the part is used for more time (upper square) than the allowable lifetime (dot) at a given temperature, it will fail; if it is used for less time (lower square) than the lifetime, it will be safe.

3.2. Four-Parameter Method 1. Four-parameter $\left(t_{0}, f_{0}, k_{1}, k_{2}\right)$ method 1 is composed of two exponential functions, and when the time is less than the reference time $t_{0}$, one function is used, as in (5). When the lifetime $t$ is zero in (5) [13], the equation can be rewritten as (6), from which $f_{c}$ is confirmed with the other three parameters $f_{0}, k_{1}$, and $t_{0}$ :

$$
\begin{aligned}
f(t) & =f_{c}-\left(f_{c}-f_{0}\right) e^{\left(t-t_{0}\right) k_{1}}: \quad\left(t<t_{0}\right) \\
100(\%) & =f_{c}\left(1-e^{\left(-t_{0} \cdot k_{1}\right)}\right)+f_{0} e^{\left(-t_{0} \cdot k_{1}\right)} \\
f_{c} & =\frac{100-f_{0} e^{\left(-t_{0} \cdot k_{1}\right)}}{1-e^{\left(-t_{0} \cdot k_{1}\right)}} .
\end{aligned}
$$

When the time is greater than the reference time $t_{0}$, the recovery equation is represented as in (8). Figure 3 schematically shows the recovery rate curve using four-parameter method 1:

$$
f(t)=f_{0} e^{-\left(t-t_{0}\right) k_{2}}: \quad\left(t>t_{0}\right) .
$$

3.3. Four-Parameter Method 2. In four-parameter $\left(t_{0}, f_{0}\right.$, $k_{1}, k_{2}$ ) method 2, $f_{c}$ is a constant and not dependent on $f_{0}$, $k_{1}$, and $t_{0}$ [14]. When the lifetime $t$ is $-\infty$, the recovery is assumed to be $100 \%$ to make the recovery curve symmetric, as in (9). Therefore, four-parameter method 2 is actually the same as method 1 , except that $f_{c}=100$ instead of the definition in (7) (Figure 4):

$$
\begin{aligned}
& f(t)=100-\left(100-f_{0}\right) e^{\left(t-t_{0}\right) k_{1}}: \quad\left(t<t_{0}\right) \\
& f(t)=f_{0} e^{-\left(t-t_{0}\right) k_{2}}: \quad\left(t>t_{0}\right) .
\end{aligned}
$$

\section{Experiments}

Before the HALT test of the VMQ, a rubber material property test was performed by the Korea Testing and Research 
TABLE 1: Material properties of VMQ.

\begin{tabular}{lcc}
\hline Material properties & Exp. value & Test standard \\
\hline Basic properties & 70 & \\
Hardness (IRHD) & 7.8 & ASTM D412 \\
Tensile strength (MPa) & 150 & \\
Ultimate elongation (\%) & 0 & \\
Heat resistance & -19.9 & ASTM D573 \\
Change in hardness (\%) & -7.6 & ASTM D395, method B; $22 \mathrm{~h}, 150^{\circ} \mathrm{C}$, plied \\
Change in tensile strength (\%) & 9.2 & ASTM D395, method B; $1000 \mathrm{~h}, 150^{\circ} \mathrm{C}$, plied \\
Change in elongation (\%) & 33.6 & \\
Compression set (\%) & & \\
Compression set (\%) & -5 & ASTM D471, ASTM oil number $1 ; 70 \mathrm{~h}, 150^{\circ} \mathrm{C}$ \\
Fluid resistance & -10.1 & \\
Change in hardness (IRHD) & -3.3 & \\
Change in tensile strength (\%) & 3.4 & ASTM D471, ASTM oil number 3; $70 \mathrm{~h}, 150^{\circ} \mathrm{C}$ \\
Change in elongation (\%) & & \\
Change in volume (\%) & -10 & ASTM D2137, method A; $-55^{\circ} \mathrm{C}, 3 \mathrm{~min}$ \\
Fluid resistance & 17.5 & No cracking \\
Change in hardness (IRHD) &
\end{tabular}

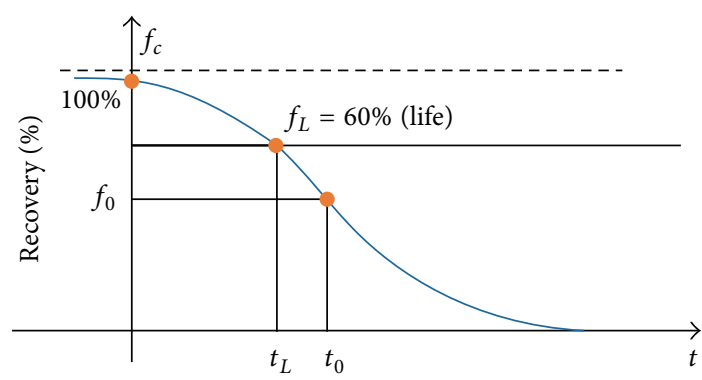

FIGURE 3: Recovery rate curve using four-parameter method 1.

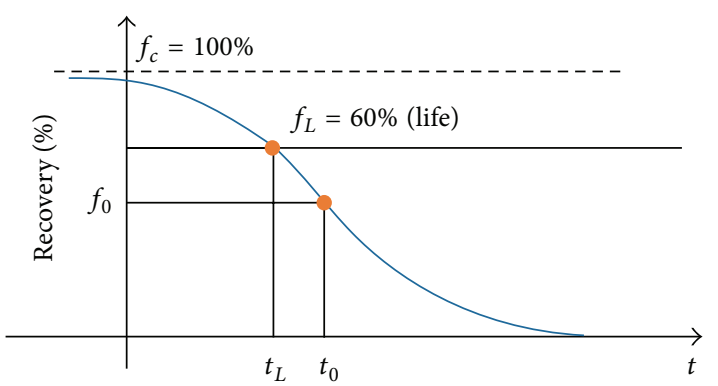

Figure 4: Recovery rate curve using four-parameter method 2. $f_{c}$ : critical recovery, $f_{L}:$ life recovery, $t_{L}:$ lifetime, $f_{0}$ : reference recovery, and $t_{0}$ : reference time.

Institute (KTR) and the Korea Polymer Testing \& Research Institute (KOPTRI) according to ASTM standards. The test results are given in Table 1.

The ability of a rubber to return to its original thickness after prolonged compression is measured by a compression set test at high and low temperatures. The compression set tests in this study were carried out under a compression rate of $30 \%$ with VMQ silicon rubber gaskets. For the lifetime prediction at a high temperature, the compression set test was performed with components that were heat-aged in an oven at temperatures of 150,180 , and $200^{\circ} \mathrm{C}$ for periods ranging from 20 to $500 \mathrm{~h}$, and a cold resistance test was performed at a temperature of $-70^{\circ} \mathrm{C}$ for periods ranging from 48 to $120 \mathrm{~h}$. The dimensions of the specimen (diameter $=29 \mathrm{~mm}$ and thickness $=12.5 \mathrm{~mm}$ ) and the compression set were determined according to ISO 815-1 (Figure 5) [15]. The compression set and recovery rate were calculated using

$$
\begin{aligned}
\operatorname{CS}(\%) & =\frac{\left(l_{0}-l_{2}\right)}{\left(l_{0}-l_{1}\right)} \times 100 \\
\operatorname{Recovery}(\%) & =100-\mathrm{CS},
\end{aligned}
$$

where CS $=$ compression set, $l_{0}=$ thickness of the specimen, $l_{1}=$ thickness in the compressed state, and $l_{2}=$ thickness after removal of the load.

Table 2 lists the experimental data for each temperature. First, the experiments were performed at $150^{\circ} \mathrm{C}$ according to method B in the ASTM D395. The higher temperature of $180^{\circ} \mathrm{C}$ was adopted for the HALT as in [3]. The temperature of $200^{\circ} \mathrm{C}$ seems rather high. The experimental data, with the exception of a couple of erroneous data points, were selected to optimize the four parameters in four-parameter methods 1 and 2 by SZGA.

\section{Results}

Representative automobile companies require the compression set rates of engine head rubber gaskets to be less than 
TABLE 2: Results of the compression set test with a compression rate of $30 \%$ at (a) high temperatures and (b) a low temperature.

(a)

\begin{tabular}{|c|c|c|c|c|c|c|c|c|c|c|c|}
\hline Temp. $\left({ }^{\circ} \mathrm{C}\right)$ & Time (h) & CS (\%) & Recov. (\%) & Temp. $\left({ }^{\circ} \mathrm{C}\right)$ & Time (h) & CS (\%) & Recov. (\%) & Temp. $\left({ }^{\circ} \mathrm{C}\right)$ & Time (h) & CS (\%) & Recov. (\%) \\
\hline \multirow{8}{*}{150} & 22 & 9.20 & 90.80 & \multirow{8}{*}{180} & 48 & 10.33 & 89.67 & \multirow{8}{*}{200} & 20 & 10.67 & 89.33 \\
\hline & 1000 & 33.60 & 66.40 & & 96 & 25.67 & 74.33 & & 30 & 18.33 & 81.67 \\
\hline & & & & & 120 & 31.00 & 69.00 & & 40 & 19.67 & 80.33 \\
\hline & & & & & 196 & 32.67 & 67.33 & & 50 & 30.00 & 70.00 \\
\hline & & & & & 240 & 34.33 & 65.67 & & 200 & 83.00 & 17.00 \\
\hline & & & & & & & & & 300 & 86.00 & 14.00 \\
\hline & & & & & & & & & 400 & 92.00 & 8.00 \\
\hline & & & & & & & & & 500 & 97.00 & 3.00 \\
\hline
\end{tabular}

(b)

\begin{tabular}{lccc}
\hline Temp. $\left({ }^{\circ} \mathrm{C}\right)$ & Time $(\mathrm{h})$ & CS $(\%)$ & Recov. $(\%)$ \\
\hline \multirow{4}{*}{-70} & 48 & 1.93 & 98.07 \\
& 72 & 2.73 & 97.27 \\
& 96 & 3.34 & 96.66 \\
& 120 & 3.78 & 96.22 \\
\hline
\end{tabular}
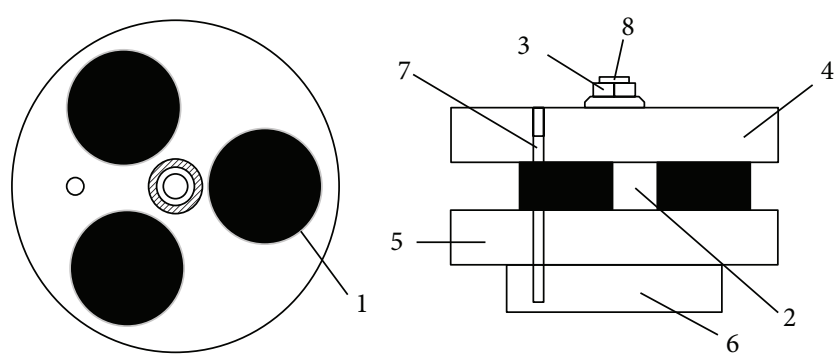

(1) Rubber sample

(5) Lower plate

(2) Spacer

(3) Nut

(4) Upper plate

(7) Position control pin

(8) Bolt

FIGURE 5: Jig for measuring the compression set.

$40 \%$. In other applications, the lifetimes of a gasket are defined as the time until its recovery rate is $60 \%$. Both heat and cold resistance tests were performed. Experimental data at each temperature were obtained from the compression set test, and the recovery rate curves were fit using the SZGA method to find the optimal parameters of the smallest MSE between the best-fit function and the experimental data. Subsequently, the lifetime of the recovery rate at $60 \%$ was obtained from the best-fit recovery rate curve using a bisection method to solve the nonlinear equation. Finally, a linear regression model was fit by superimposing the recovery rate curve on the Arrhenius plot to obtain the long-term lifetime at the working temperature.

5.1. Lifetime of VMQ Gaskets under High Temperatures. The lifetime evaluations have been made on the two differently regressed curves of methods 1 and 2 .

TABLE 3: MSEs of the four-parameter methods at a compression rate of $30 \%$.

\begin{tabular}{lcccc}
\hline Method & \multicolumn{3}{c}{ MSE } & Total MSE \\
& $150^{\circ} \mathrm{C}$ & $180^{\circ} \mathrm{C}$ & $200^{\circ} \mathrm{C}$ & \\
\hline Four-parameter method 1 & 0 & 10.432 & 3.998 & 14.430 \\
Four-parameter method 2 & 0 & 6.712 & 3.988 & 10.700 \\
\hline
\end{tabular}

5.1.1. Recovery Rate Curves from Four-Parameter Methods 1 and 2. The recovery rate curves were acquired using fourparameter methods 1 and 2. The SZGA method was used to optimize the four parameters, and the recovery rate curves of the two methods were fit using these four parameters. The recovery rate curves were compared with the experimental data. The results showed that the recovery rate curves could be fit properly using the four parameters. Figures 6 and 7 [14, 16] show the recovery rate curves at different temperatures and a compression rate of $30 \%$.

5.1.2. Mean Squared Error of Four-Parameter Methods 1 and 2. The MSE [12] can be calculated to gauge the extent to which the data points vary from the recovery rate curves. Table 3 compares the MSEs of four-parameter methods 1 and 2. For the life prediction of the rubber gasket, either method can be used to find the least MSE:

$$
\text { Mean squared error }(\mathrm{MSE})=\frac{1}{n} \sum_{i=1}^{n}\left(y_{i}-\widehat{y}_{i}\right)^{2} \text {. }
$$

One can see that four-parameter method 2 yields a smaller MSE than method 1 for a compression rate of $30 \%$.

5.1.3. Results of Quantitative Lifetime Prediction. Compression set rates less than $40 \%$ are required by major automobile 

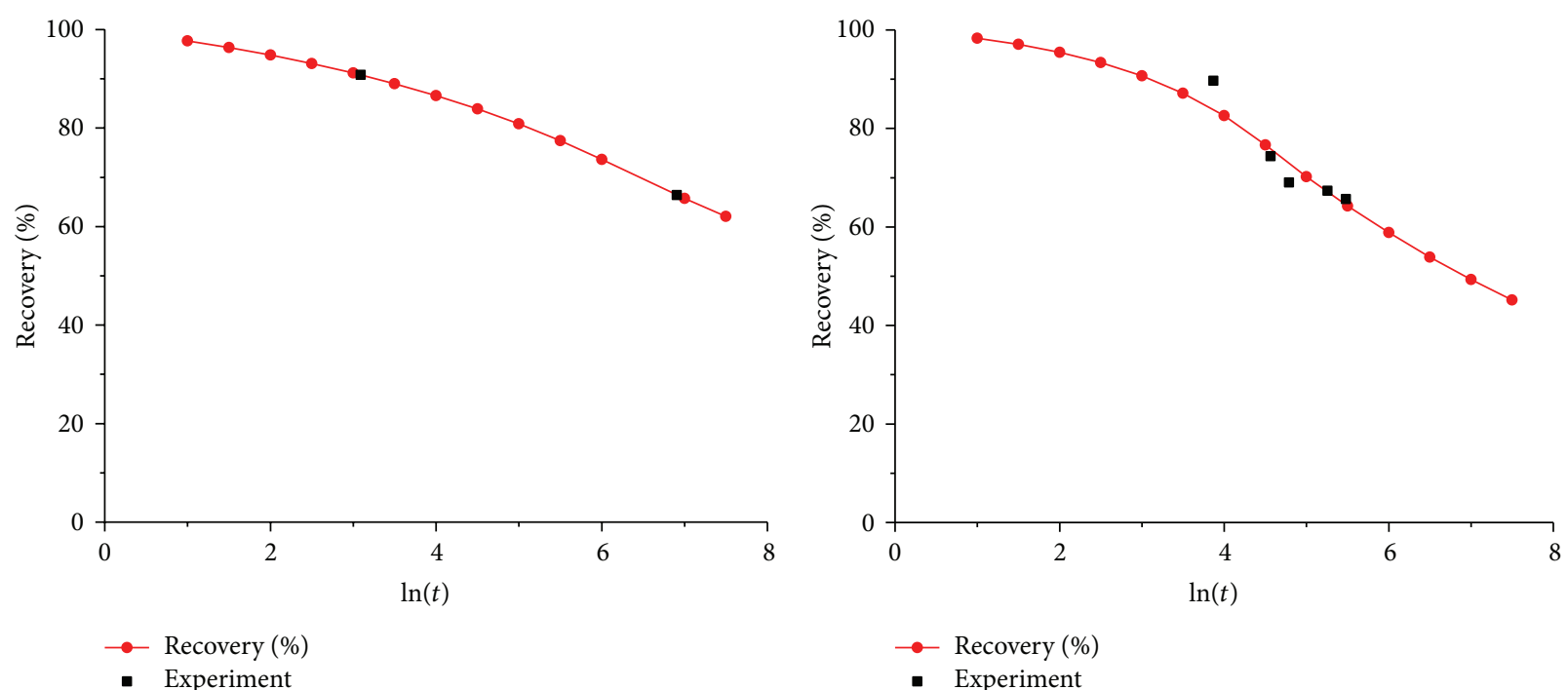

(a)

(b)

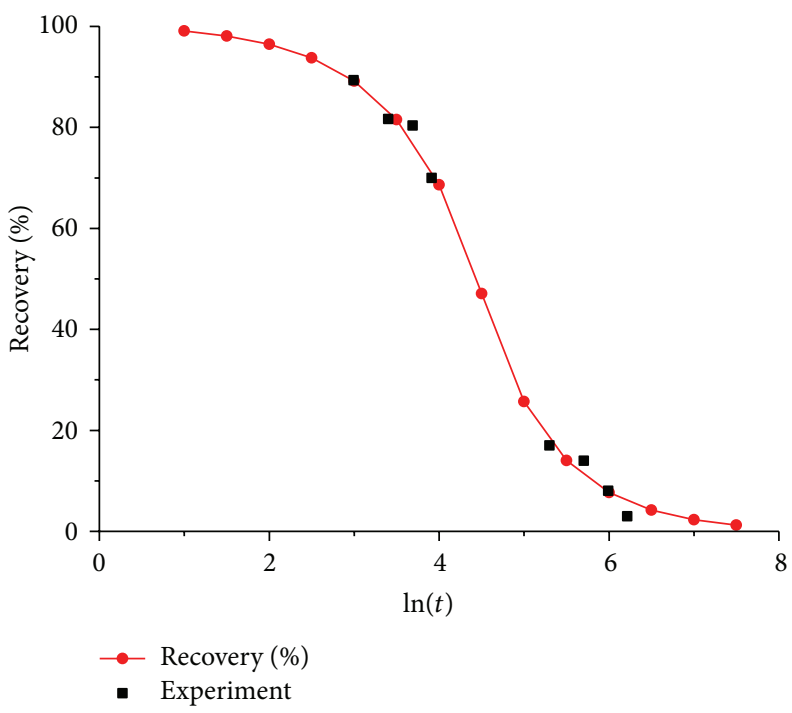

(c)

Figure 6: Recovery rate curves using four-parameter method 1 with a compression rate of $30 \%$ at temperatures of (a) $150^{\circ} \mathrm{C}$, (b) $180^{\circ} \mathrm{C}$, and (c) $200^{\circ} \mathrm{C}$.

companies. The precise lifetime corresponding to a recovery rate of $60 \%$ can be determined using the bisection method from the four-parameter equations. The method with the minimum MSE is the best choice to obtain the lifetime with a $60 \%$ recovery rate. The lifetime data acquired from each recovery rate curve were plotted using linear regression, and a linear equation was derived using the Origin Pro system (Figure 8). This equation can be used to estimate the lifetime at a specific temperature from the Arrhenius equation. Subsequently, the lifetime and lifetime mileage were calculated by

Time (hour) $=\exp \{\ln (t)\}$

Life mile $=30 \mathrm{mph}($ mile $/$ hour $) \times$ time (hour).
Under operating conditions of $30 \mathrm{mph}$ (mile/hour) at $100^{\circ} \mathrm{C}$, the lifetime mileage values of the rubber gasket predicted by four-parameter methods 1 and 2 are 6,836,220 and 7,805,780 mi, respectively, as shown in Table 4 . Because the operating time is assumed to be an average of $3 \mathrm{~h} /$ day, the predicted quantitative lifetimes of the rubber gasket calculated using four-parameter methods 1 and 2 are 208 and 273 years, respectively. Thus, the lifetime of the VMQ silicon rubber gasket predicted at a working temperature of $100^{\circ} \mathrm{C}$ meets the performance requirements of $100,000 \mathrm{mi}$ and 10 years.
5.2. Lifetime of VMQ Gaskets under Low Temperatures. A closer look at the experimental data at a low temperature 
TABLE 4: Lifetime mileage determined using the Arrhenius equation.

\begin{tabular}{|c|c|c|c|}
\hline \multicolumn{4}{|c|}{ Compression rate $30 \%$} \\
\hline \multicolumn{2}{|c|}{ Four-parameter method 1} & \multicolumn{2}{|c|}{ Four-parameter method 2} \\
\hline \multicolumn{2}{|c|}{$\ln (t)=14.06674 \times\left\{\left(1 /\left(T\left({ }^{\circ} \mathrm{C}\right)+273\right)\right) \times 1000\right\}-26.37589$} & \multicolumn{2}{|c|}{$\ln (t)=14.39015 \times\left\{\left(1 /\left(T\left({ }^{\circ} \mathrm{C}\right)+273\right)\right) \times 1000\right\}-26.11032$} \\
\hline Temperature $\left({ }^{\circ} \mathrm{C}\right)$ & Lifetime mileage $\left(10^{3}\right.$ miles $)$ & Temperature $\left({ }^{\circ} \mathrm{C}\right)$ & Lifetime mileage ( $10^{3}$ miles $)$ \\
\hline 80 & 57,911 & 80 & 69,453 \\
\hline 100 & 6,836 & 100 & 7,805 \\
\hline 120 & 1,003 & 120 & 1,095 \\
\hline 140 & 177 & 140 & 186 \\
\hline 160 & 36 & 160 & 37 \\
\hline 180 & 9 & 180 & 9 \\
\hline
\end{tabular}

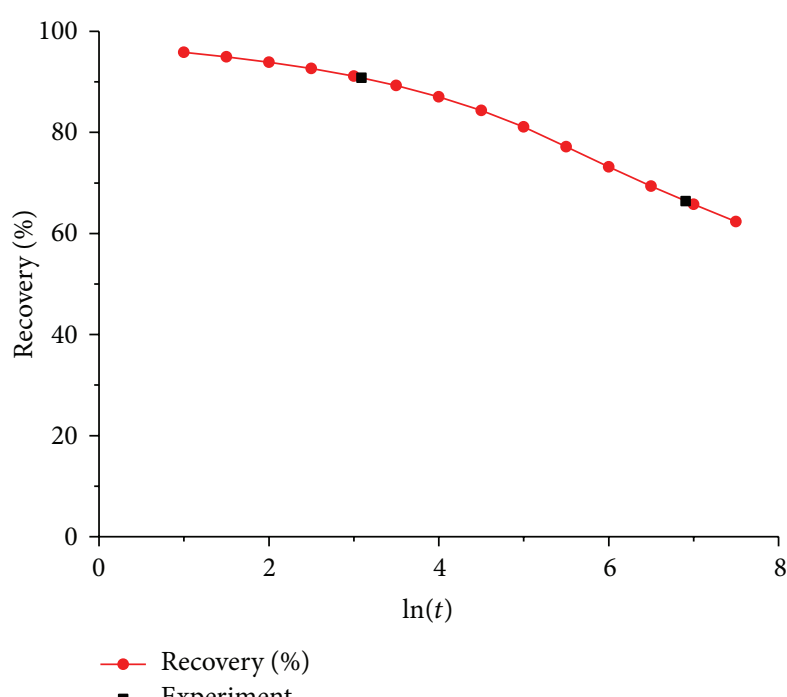

- Experiment

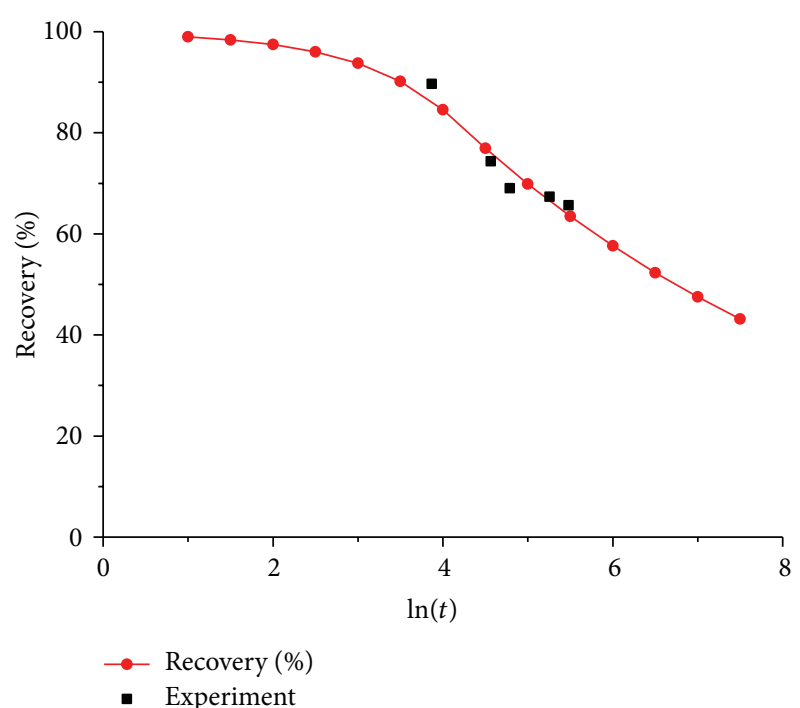

(b)

(a)

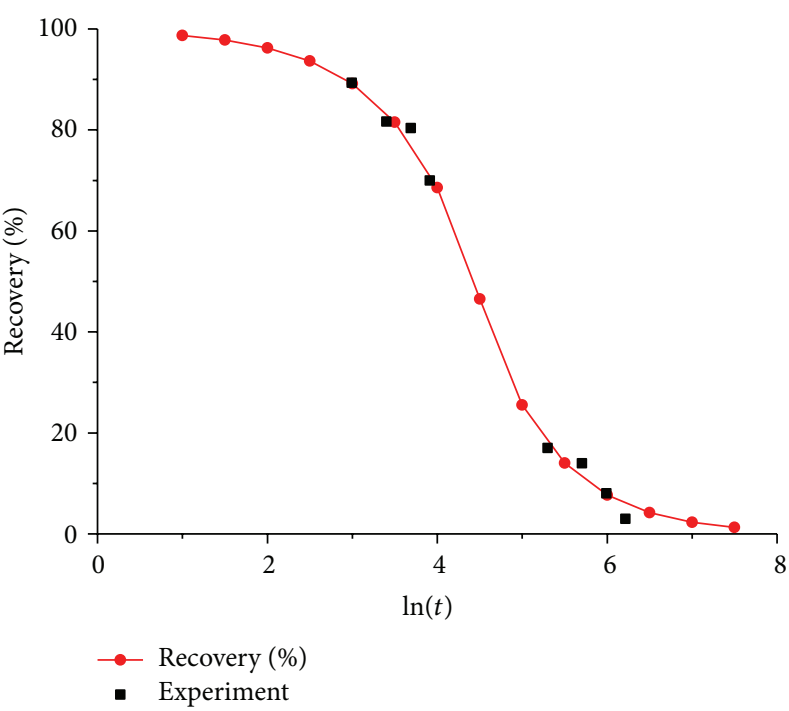

(c)

Figure 7: Recovery rate curves using four-parameter method 2 with a compression rate of $30 \%$ at temperatures of (a) $150^{\circ} \mathrm{C}$, (b) $180^{\circ} \mathrm{C}$, and (c) $200^{\circ} \mathrm{C}$. 


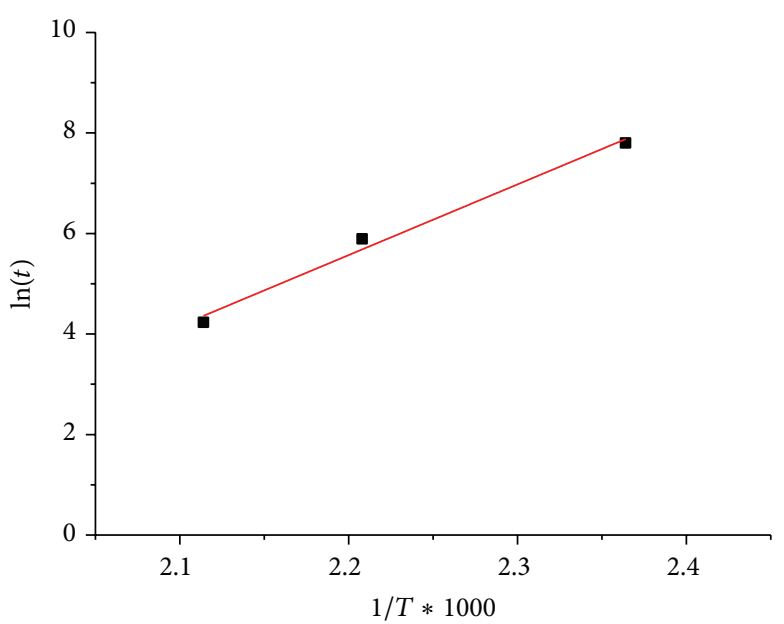

- Life data

- Life line

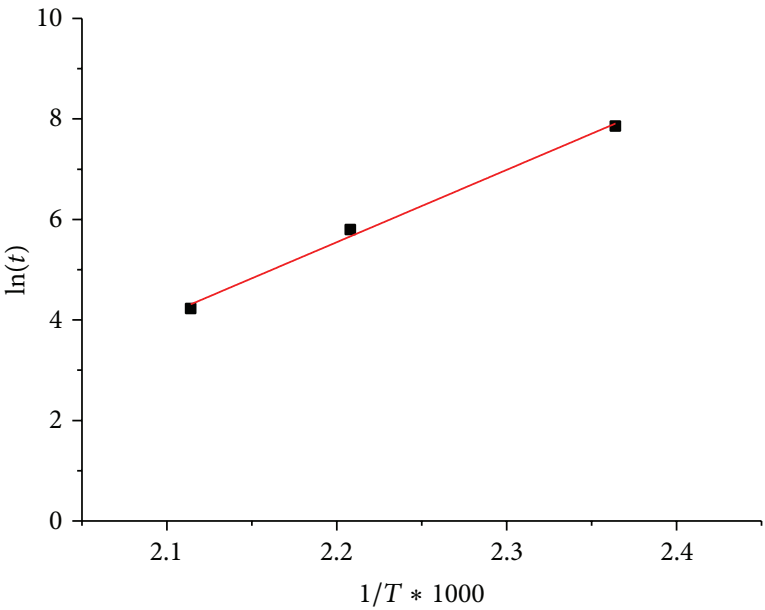

- Life data

Life line

(a)

(b)

FIgURE 8: Arrhenius plots for four-parameter methods (a) 1 and (b) 2.

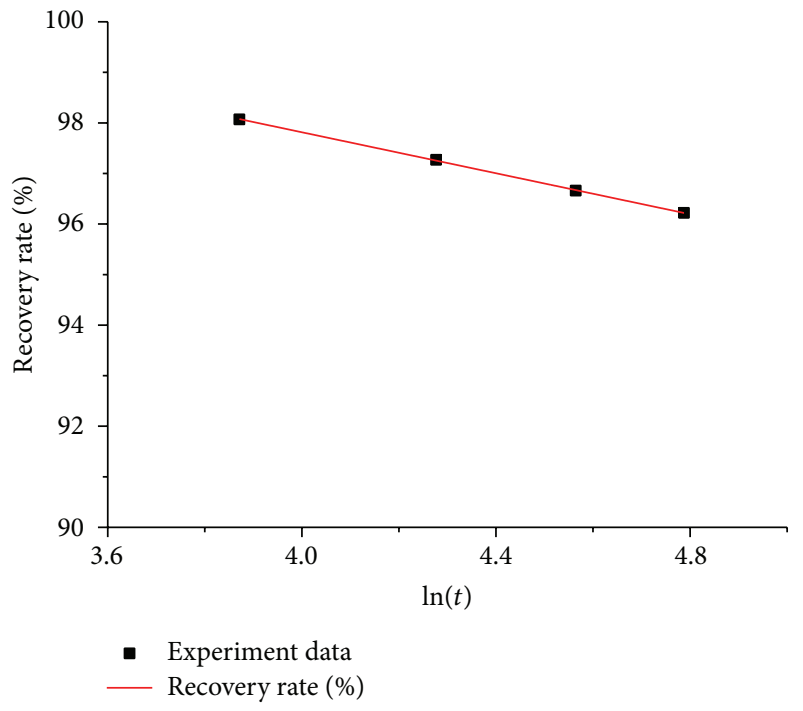

Figure 9: Recovery rate curve at low temperature $\left(-70^{\circ} \mathrm{C}\right)$.

(Table 2(b)) indicates that the relationship between the recovery rate and lifetime can be represented as a straight line. Thus, a linear regression was performed using the experimental data from the compression set test at a low temperature, and the intercept and slope of the linear equation were obtained. This means that only two parameters were needed to predict the lifetime, unlike in the four-parameter methods. Figure 9 shows the regression line from the linear relation between the recovery rate and lifetime. In cold regions, like the Antarctic, where temperatures can reach $-70^{\circ} \mathrm{C}$, shrinkage and shrinkage leaking in the rubber may occur because of the low temperatures, and these problems can reduce the recovery rate of VMQ. Thus, the standard required recovery rate of over $60 \%$ should be applied to predict
TABLE 5: Lifetimes from the fitted line.

\begin{tabular}{lccc}
\hline \multicolumn{4}{c}{ Recovery rate $(\%)=-2.02719 \times \ln (t)+105.92382$} \\
Time $(\mathrm{h})$ & $\ln (t)$ & Compressed set $(\%)$ & Recovery rate $(\%)$ \\
\hline 2,579 & 7.8552 & 10 & 90 \\
30,384 & 10.3217 & 15 & 85 \\
357,960 & 12.7882 & 20 & 80 \\
$4,217,197$ & 15.2547 & 25 & 75 \\
$49,683,641$ & 17.7212 & 30 & 70 \\
\hline
\end{tabular}

the lifetime in this case. Table 5 shows the lifetime of the rubber gasket obtained from the best-fit line at different recovery rates ranging from 70 to $90 \%$. After establishing the standard recovery rate, depending on the method and purpose of use, the lifetime of VMQ can be predicted for each case. For example, according to the linear equation, the lifetime of the VMQ rubber gasket corresponding to a recovery rate of $80 \%$ was $357,960 \mathrm{~h}$. Assuming that the rubber gasket in an automobile radiator is continuously exposed to temperatures of $-70^{\circ} \mathrm{C}$, its lifetime would be 41 years. This result leads to the conclusion that the VMQ rubber gasket sufficiently satisfies the lifetime requirement of 10 years.

\section{Conclusion}

A compression set test was carried out on developed VMQ gaskets at a compression rate of 30\%. The SZGA method was applied to determine the optimal four parameters for the two four-parameter methods used in this study and calculate the recovery rate curves. The MSEs of the regression functions from different models and the experimental data were compared. By comparing the results of both methods, it was determined that either method can be used to accurately predict gasket lifetime because they showed only small 
differences in their results. We obtained the target lifetime for a recovery rate of $60 \%\left(80 \%\right.$ for $\left.-70^{\circ} \mathrm{C}\right)$ through the fitted recovery rate curve using the bisection method at each temperature.

Referring to the data points of the $60 \%\left(80 \%\right.$ for $\left.-70^{\circ} \mathrm{C}\right)$ recovery found from the recovery rate curves, a linear Arrhenius plot in the $\ln (t)-(1 / T)$ plane was constructed to determine the quantitative lifetime at any given temperature.

The results are summarized as follows.

(1) A procedure using four-parameter methods 1 and 2 to predict the long-term lifetimes of rubber gaskets was suggested.

(2) Using four-parameter methods 1 and 2, the quantitative lifetime of a rubber gasket could be accurately predicted at any given temperature.

(3) The lifetime mileage of VMQ was predicted to be $6,836,220$ and $7,805,780 \mathrm{mi}$ using four-parameter methods 1 and 2, respectively, at a working temperature of $100^{\circ} \mathrm{C}$.

(4) The lifetime of the VMQ rubber is 41 years at an ambient temperature of $-70^{\circ} \mathrm{C}$ based on the standard recovery rate of $80 \%$.

\section{Conflict of Interests}

The authors declare that there is no conflict of interests regarding the publication of this paper.

\section{Acknowledgments}

This study was carried out under the Small and Medium Business Technology Development Program supported by the Small and Medium Business Administration of the Republic of Korea. The authors are partially supported by the BK21 Plus Project of the Korea Research Foundation.

\section{References}

[1] A. N. Gent, Engineering with Rubber: How to design Rubber Components, Hanser Publishers, 2nd edition, 2005.

[2] Wikipedia, "Synthetic rubber," 2015, http://en.wikipedia.org/ wiki/Synthetic_rubber.

[3] Y.-D. Kwon, K.-T. Roh, S.-S. Kim, and J.-H. Doh, "Regression of the recovery rate of acm rubber gasket for long-term performances," Journal of Testing and Evaluation, vol. 42, no. 3, 2014.

[4] W. D. Kim, W. S. Kim, and C. S. Woo, "Prediction of useful life by heat aging of motor fan isolating rubber," Elastomers and Composites, vol. 37, no. 2, pp. 107-114, 2002.

[5] Wikipedia, "Highly Accelerated Life Test," 2008, http://en.wikipedia.org/wiki/Highly_accelerated_life_test.

[6] Wikipedia, "Arrhenius plot," 2013, http://en.wikipedia.org/wiki/ Arrhenius_plot.

[7] NIST/SEMATECH e-Handbook of Statistical Methods, 2006, http://www.itl.nist.gov/div898/handbook/.

[8] International Organization for Standardization (ISO), ISO 11346:2014, Rubber, Vulcanized or Thermoplastic_Estimation of Life-Time and Maximum Temperature of Use, International Organization for Standardization, London, UK, 2014.
[9] C. S. Woo, S. S. Choi, S. B. Lee, and H. S. Kim, "Useful lifetime prediction of rubber components using accelerated testing," IEEE Transactions on Reliability, vol. 59, no. 1, pp. 11-17, 2010.

[10] Y.-D. Kwon, S.-B. Kwon, S.-B. Jin, and J.-Y. Kim, "Convergence enhanced genetic algorithm with successive zooming method for solving continuous optimization problems," Computers \& Structures, vol. 81, no. 17, pp. 1715-1725, 2003.

[11] Y. D. Kwon, H. W. Kwon, W. J. Kim, and S. D. Yeo, "Estimation of rubber material property by successive zooming genetic algorithm," Journal of Solid Mechanics and Materials Engineering, vol. 1, no. 6, pp. 815-826, 2007.

[12] Wikipedia, “Mean Squared Error,” 2012, http://en.wikipedia.org/ wiki/Synthetic_rubber.

[13] H.-S. Lee, C. Kim, Y.-D. Kwon, and J.-H. Doh, "Long-term life prediction of polyacrylate rubber (ACM) gasket with chlorine cure sites using the four-parameter recovery model," Proceedings of the Institution of Mechanical Engineers, Part D: Journal of Automobile Engineering, vol. 227, no. 11, pp. 1536-1545, 2013.

[14] Y.-D. Kwon, K.-S. Lee, S.-H. Jun, and H.-S. Lee, "Improvement of long-term lives of rubber gaskets of polyacrylate (ACM) by employing carboxyl cure sites," International Journal of Automotive Technology, vol. 15, no. 1, pp. 39-45, 2014.

[15] Korea Agency for Technology and Standard, "Rubber, Vulcanized or Thermoplastic-Determination of Compression setPart 1: At Ambient or Elevated Temperatures," KS M ISO 815-1, KATS, Seoul, Republic of Korea, 2010.

[16] Hankook Sealtech, "The development of the engine head cover gasket using the polyacrylate (ACM) rubber," Report S1071413, Hankook Sealtech, 2012. 


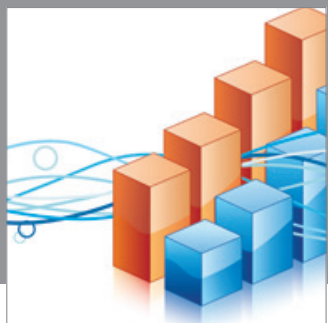

Advances in

Operations Research

mansans

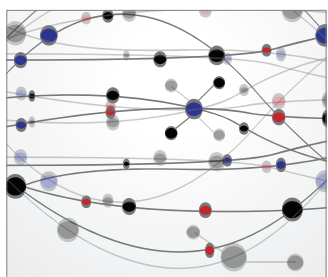

The Scientific World Journal
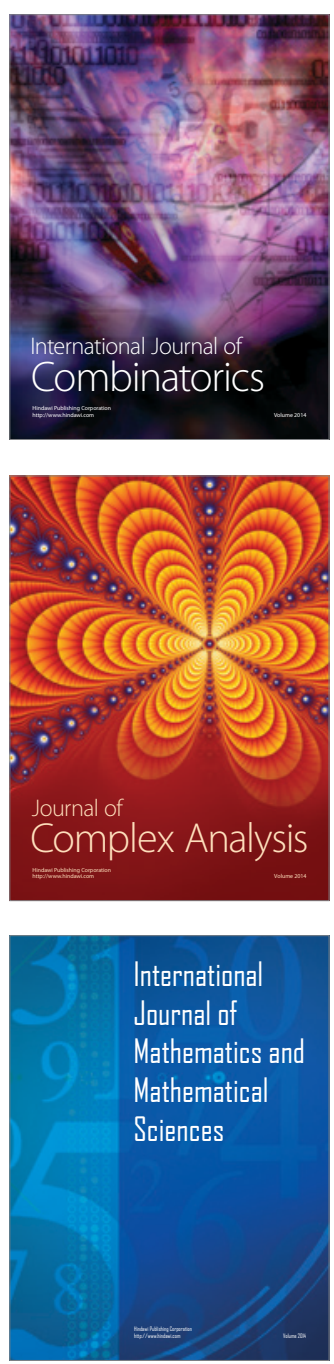
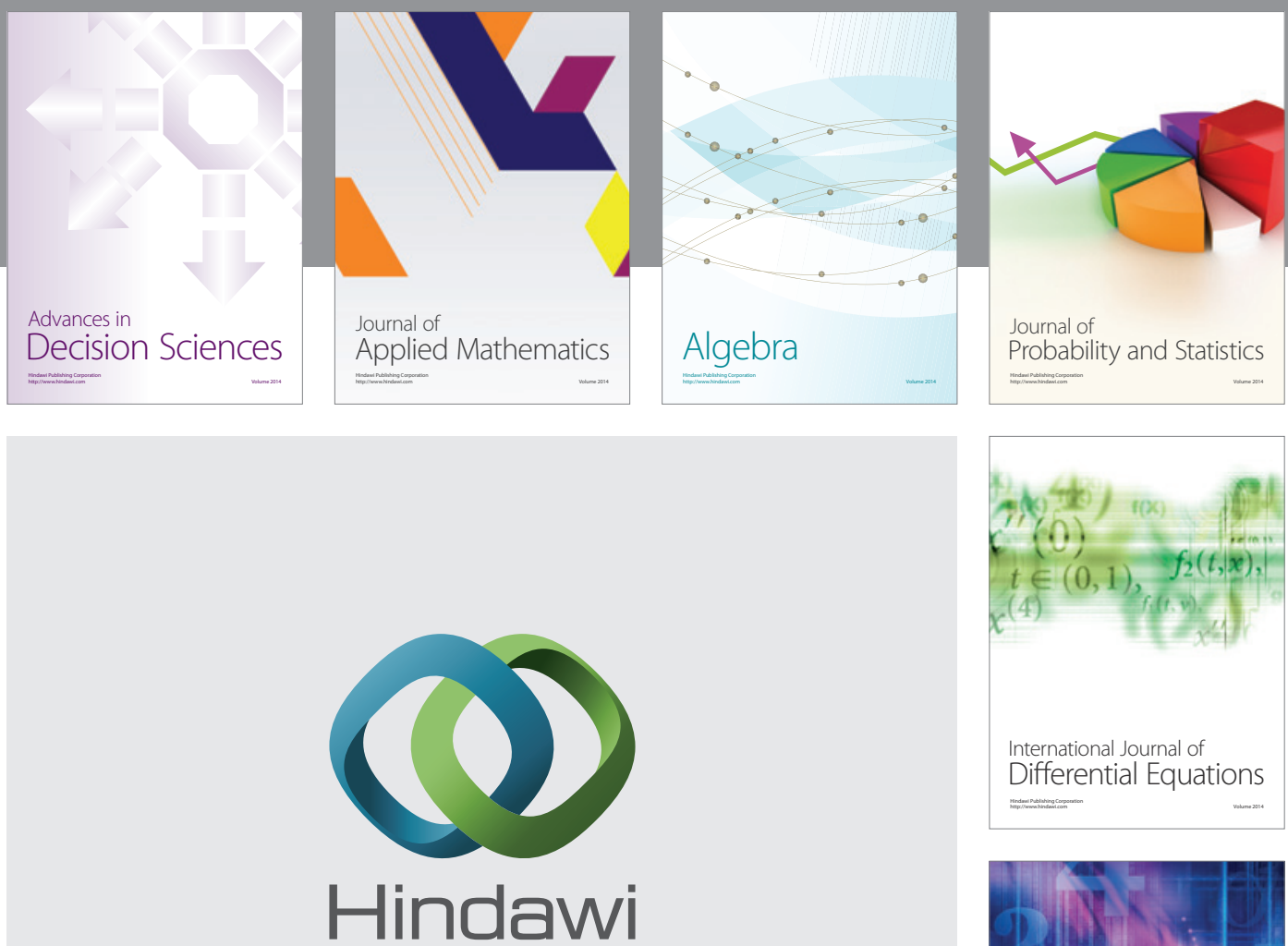

Submit your manuscripts at http://www.hindawi.com
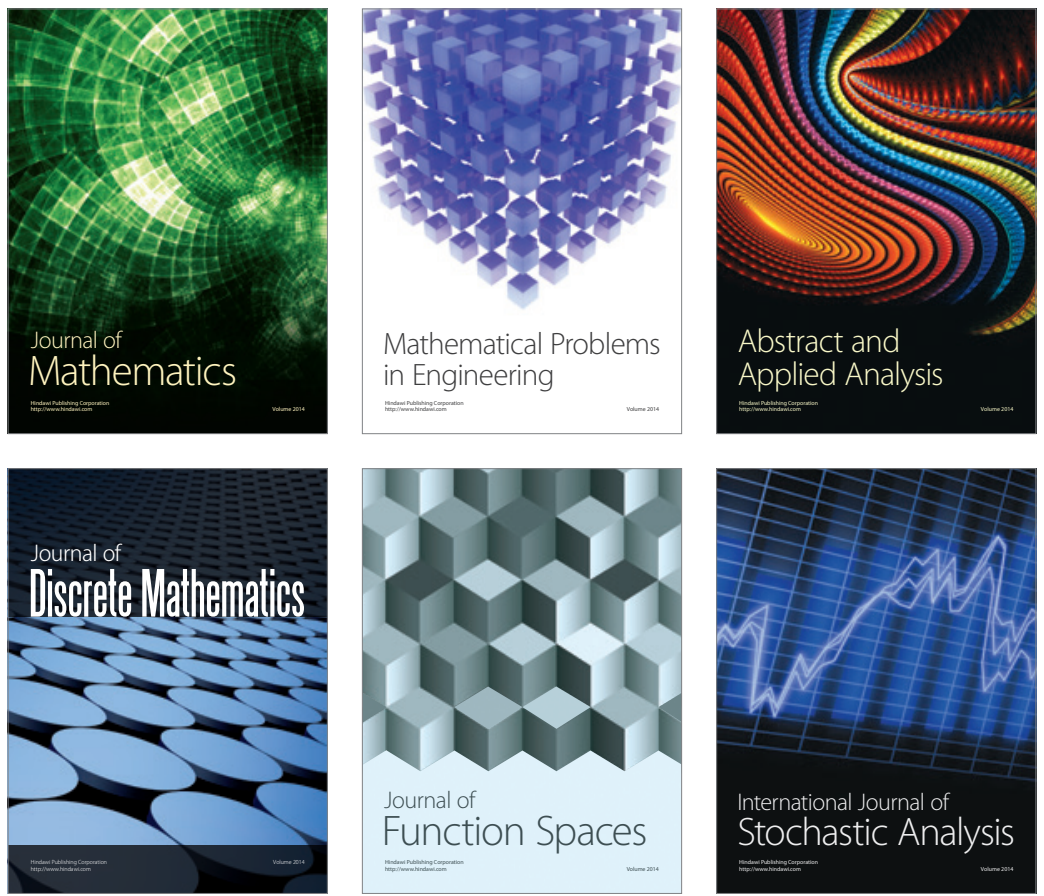

Journal of

Function Spaces

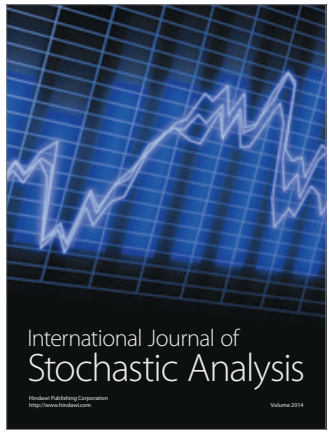

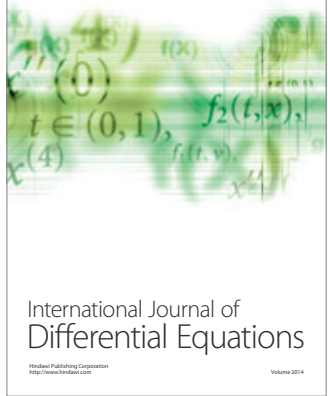
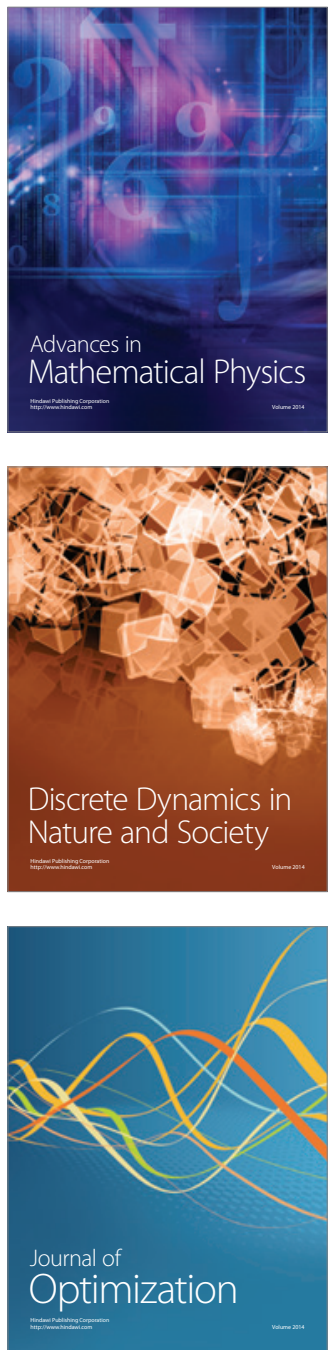